\title{
Relation of head posture and occlusal contact area using photo occlusion analysis
}

\author{
Chang-Hwan Kim, Kyung-Ho Ko, Yoon-Hyuk Huh, Lee-Ra Cho, Chan-Jin Park* \\ Department of Prosthodontics and Research Institute of Oral Science, College of Dentistry, Gangneung-Wonju National University, \\ Gangneung, Republic of Korea
}

Purpose: Previous studies related with occlusal contact area were limited that interocclusal thickness level or the method of measurement has not been accurate in measuring. The purpose of this study was to investigate the relation between head posture and occlusal contact area using photo occlusion analysis. Materials and Methods: 54 subjects with complete dentition (44 men, 10 women / 23 to 33 years of age) were included. To identify the relationship between head posture and occlusal contact area, subjects took interocclusal record in maximal intercuspal position with three different positions(supine position $\left(0^{\circ}\right) /$ inclined position $\left(45^{\circ}\right)$ / upright position $\left(90^{\circ}\right)$ ) on the dental unit chair. Occlusal contact area was analyzed using photo occlusion analysis. Statistical analyses were performed with SPSS ver.25.0 at 95\% confidence interval. Results: Head posture has no significant effect on the changes of occlusal contact area $(P>0.05)$. Conclusion: When interocclusal relation is stable, head posture does not change a interocclusal record because head posture has no significant effect on occlusal contact area. Analysis of occlusal contact area using photo occlsion analysis device is useful due to its material property and simplicity. (J Dent Rehabil Appl Sci 2019;35(2):90-7)

Key words: occlusal contact area; head posture; photo occlusion anaylsis; maximal intercuspal position

\section{서론}

저작단계에서는 교합력, 저작패턴, 교합접촉 수나 교 합접촉면적 등 다양한 요소가 관련된다. 이 중 교합접촉 면적은 저작단계에서 음식물이 분쇄될 때 관계되는 요소 중 하나이다. ${ }^{1-3}$ 저작 시 교합접촉이 일어나는 부위는 음 식의 분쇄가 가능한 영역이 되는데, 교합접촉은 수직적 인 폐구상태와 동적인 측방 운동시의 나타나게 된다. ${ }^{2}$ 정 적인 수직적 폐구상태의 교합접촉면적은 저작효율, 선호 저작측, 부기능 습관, 교정치료, 머리 위치와 같은 다양한 요소들과 관련되어 있다고 여겨져 왔다.

교합접촉면적이 넓다면 음식의 분쇄가 일어나는 영역 이 넓어지므로 저작효율이 높아진다고 여겨졌다. ${ }^{2}$ 하지

*Correspondence to: Chan-Jin Park

Professor, Department of Prosthodontics and Research Institute of Oral Science, College of Dentistry, Gangneung-Wonju National University, Jukheon-gil 7, Gangneung, 25457, Republic of Korea

Tel: +82-33-640-3153, Fax: +82-33-640-3103, E-mail: doctorcj@gwnu.ac.kr

Received: April 9, 2019/Last Revision: May 2, 2019/Accepted: May 21, 2019
만 저작효율과 교합접촉면적에 대해 논쟁적인 결과들이 나타났는데, 저작효율을 측정하는 방법과 저작효율에 관 계되는 요소가 매우 다양하기 때문으로 추측된다..$^{4-7}$ 저 작효율에 대해 한 사람에서는 교합접촉면적에 따라 저작 효율의 차이가 나타났으나, 사람 간에선 교합접촉면적에 따른 저작효율의 관계는 나타나지 않았음을 보고한 연 구가 있었던 반면 ${ }^{4}$ 교합접촉면적에 따라 사람 간 차이가 나타나고 ${ }^{5}$ 교합접촉면적과 약한 양성 관계를 보였다는 연구가 있었다. ${ }^{6-8}$

환자의 자세, 특히 머리위치와 관련된 연구를 살펴보면 Gupta 등 ${ }^{9}$ 은 총의치 대상자와 자연치열 대상자에서 자세 를 비교하여 차이가 나타났음을 보고하였다. 하지만 그 외 대다수는 하악 위치나 하악 과두의 위치와 머리 위치 
의 관련성에 대한 연구였다. ${ }^{10-12}$ 또 앞으로 누운 자세에서 연구가 이루어진 경우가 많았다. ${ }^{9,11,12}$ 뒤로 누운 자세에서 의 교합접촉면적의 비교나 실리콘 악간관계기록재를 이 용한 정밀한 교합접촉면적의 비교는 없었다.

임상적으로 교합접촉은 치아 간 거리가 매우 작은 부 위를 나타내므로 실제 교합접촉이 일어나는 면적만을 측 정하는 것은 어렵다. 또한, 측정에 이용하는 재료가 그 자 체로 두께를 갖고 있다는 것도 면적 측정을 어렵게 하는 요소이다. ${ }^{13}$ 예를 들어 교합지는 shimstock과 같이 약 8 $\mu \mathrm{m}$ 정도 수준에서부터 ${ }^{14}$ 두껍게는 $200 \mu \mathrm{m}$ 수준까지 다 양하다. ${ }^{15}$ 한편, 특수한 목적이나 연구 등을 위해 교합접 촉면적을 측정하기 위한 재료로 사용되어 온 것은 악간 관계기록용 실리콘, 치과용 왁스, 압력 감지 센서(Dental Prescale ${ }^{\circledR}$, Fuji Film, Tokyo, Japan) 등이 있다. ${ }^{16}$ 하지만 치과용 왁스는 정밀하지 못하고 ${ }^{17}$ 압력 감지 센서는 두께 가 두꺼워 결과에 영향을 준다는 보고가 있다. ${ }^{13,15}$ 악간 관계기록용 실리콘은 높은 흐름성과 함께 교합접촉 위치 에서 재료의 두께가 거의 없어 정밀하다는 장점이 있다. ${ }^{16}$ 하지만 결과 분석 등에 있어 복잡한 과정이 필요하다. ${ }^{6,7}$

교합접촉면적 분석장치로 사용된 것은 대표적으로 Tscan (Tekscan Inc., Boston, USA)과 압력 감지 센서 장치 가 널리 사용되었다. 하지만 T-scan 장치는 교합접촉면적 이나 교합력의 상대적 비율을 확인하는데 유용한 장치이 고 $^{18}$ 압력 감지 센서는 앞서 언급한 바와 같이 센서의 두 께 때문에 한계가 있다. ${ }^{13,15}$ 그 외에도 과거의 연구들이 교 합접촉면적의 측정 단위가 작게는 $50 \mu \mathrm{m}$ 에서 크게는 350 $\mu \mathrm{m}$ 로 정밀하지 못하였고 ${ }^{5-7}$ 측정 방법에 있어서 정밀도 가 떨어지는 왁스를 사용하거나 ${ }^{4,6}$ 모형 상 마모면적을 이 용하는 등 ${ }^{8}$ 한계를 드러내었다는 점을 볼 때 교합접촉면 적에 관련된 요인에 대한 더욱 세부적이고 자세한 분석이 가능한 장치가 요구되었다. 교합접촉면적 분석장치 중 하 나인 BiteEye ${ }^{\circledR}$ (GC Dental Products corporation, Tokyo, Japan) 장치는 광조사교합분석법(photo occlusion analysis)을 이용해 프로그램 상에서 간단하게 분석 및 교합접 촉면적 정보의 채득이 가능하다. ${ }^{19}$ 분석 재료는 악간관계 기록용 실리콘을 사용하므로 실리콘의 장점인 흐름성과 정밀성을 갖출 수 있으면서도 단점으로 지적되어온 결과 분석의 복잡성을 극복할 수 있다. 한편 측정단위 역시 작 게는 $4 \mu \mathrm{m}$ 에서 크게는 $20 \mu \mathrm{m}$ 단위로 매우 정밀하고, 치 아마다의 분석이 프로그램 상에서 가능하여 각각의 치아 단위나 전치, 소구치, 대구치 단위 등으로 자세하게 분석 가능한 장점이 있다. 이를 통해 기존 연구의 한계점인 정
밀성의 부족을 극복할 수 있을 것으로 기대된다.

이 연구의 목적은 머리 위치가 교합접촉면적에 미치는 영향이 있는지 여부를 광조사교합분석장치인 BiteEye ${ }^{\circledR}$ 를 이용해 알아보는 것이다. 귀무가설은 머리 위치는 교 합접촉면적에 미치는 영향이 없다로 하였다.

\section{연구 재료 및 방법}

건전한 치열을 가진 54명(남성 44명, 여성 10명, 23 33 세)을 대상으로 강릉원주대학교 치과병원 임상시험윤 리위원회의 심의를 통과한 후 시험을 진행하였다 $(\mathrm{GW}-$

NUDH IRB 2018-008).

고정성 수복물이 없는 완전한 자연치열을 갖고 있고 교정치료를 받은 경우 완료한 지 1 년 이상의 기간이 경과 한 환자를 대상으로 하였다. 치주질환, 악관절 질환이 존 재하는 경우, 교정치료가 진행 중인 경우, 제 3 대구치가 교합하고 있는 경우의 사람은 시험 대상에서 배제하였 다. 포함 및 배제조건을 판별하기 위해 턱관절 질환 증상 존재 여부와 교정치료 진행 중 여부를 확인하였다.

광조사교합분석법을 이용하는 광조사교합분석기(Bi$\left.\mathrm{teEye}^{\circledR}\right)$ 를 이용할 때 사용하도록 지정된 재료인 폴리비 닐 실록산 성분의 실리콘 재료(Fit Checker ${ }^{\mathrm{TM}}$ Advanced Blue, GC Dental Products corporation)가 사용되었다.

머리 위치와 교합접촉면적의 관계를 알아보기 위해 시 험대상은 치과용 유닛체어에 세 가지 자세에서 악간관 계기록을 채득하였다(Fig. 1). 머리 위치는 바닥에 대한 수직선과 Camper's line이 이루는 각도에 따라 누운 자 세 시 $0^{\circ}$ (Fig. $1 \mathrm{~A}$ ), 기울인 자세 시 $45^{\circ}$ (Fig. $\left.1 \mathrm{~B}\right)$, 직립 자 세 시 $90^{\circ}$ (Fig. 1C)가 되도록 하였다. 각 자세에서 시험대 상의 하악 치아 전체의 교합면 상방으로 악간관계기록 재료를 도포하고 시험대상으로 하여금 최대교두감합위 (maximal intercuspal position, MICP)로 물도록 하였다. 제조사의 지시에 따라 시험대상은 60 초 간 최대감합위 를 유지하였다. 이 후 악간관계기록재료가 완전히 경화 된 것을 확인하고 시험대상의 구내로부터 기록을 채득하 였다. 채득한 악간관계기록은 분석의 정확도를 위해 불 필요한 부위를 잘라내었다(Fig. $2 \mathrm{~A}$ and $2 \mathrm{~B}$ ). 그리고 기 록 상 교합평면이 일정한 높이(약 $5 \mathrm{~mm})$ 에 있으면서 수 평면과 평행하게 조정하였다. 채득한 기록은 자세에 따 라 누운 자세(group S), 기울인 자세(group I), 직립 자세 (group U)로 그룹을 나누었다.

광조사교합분석기를 이용하여 교합접촉면적을 분석하 

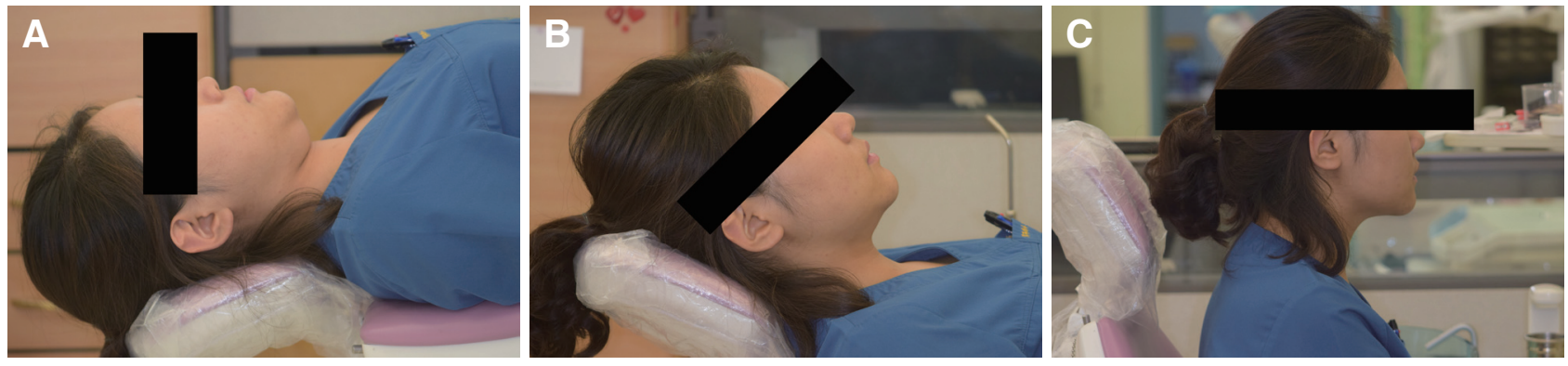

Fig. 1. Head postures. (A) Supine position $\left(0^{\circ}\right.$, group S), (B) Inclined position $\left(45^{\circ}\right.$, group I), (C) Upright position (90 ${ }^{\circ}$, group U).
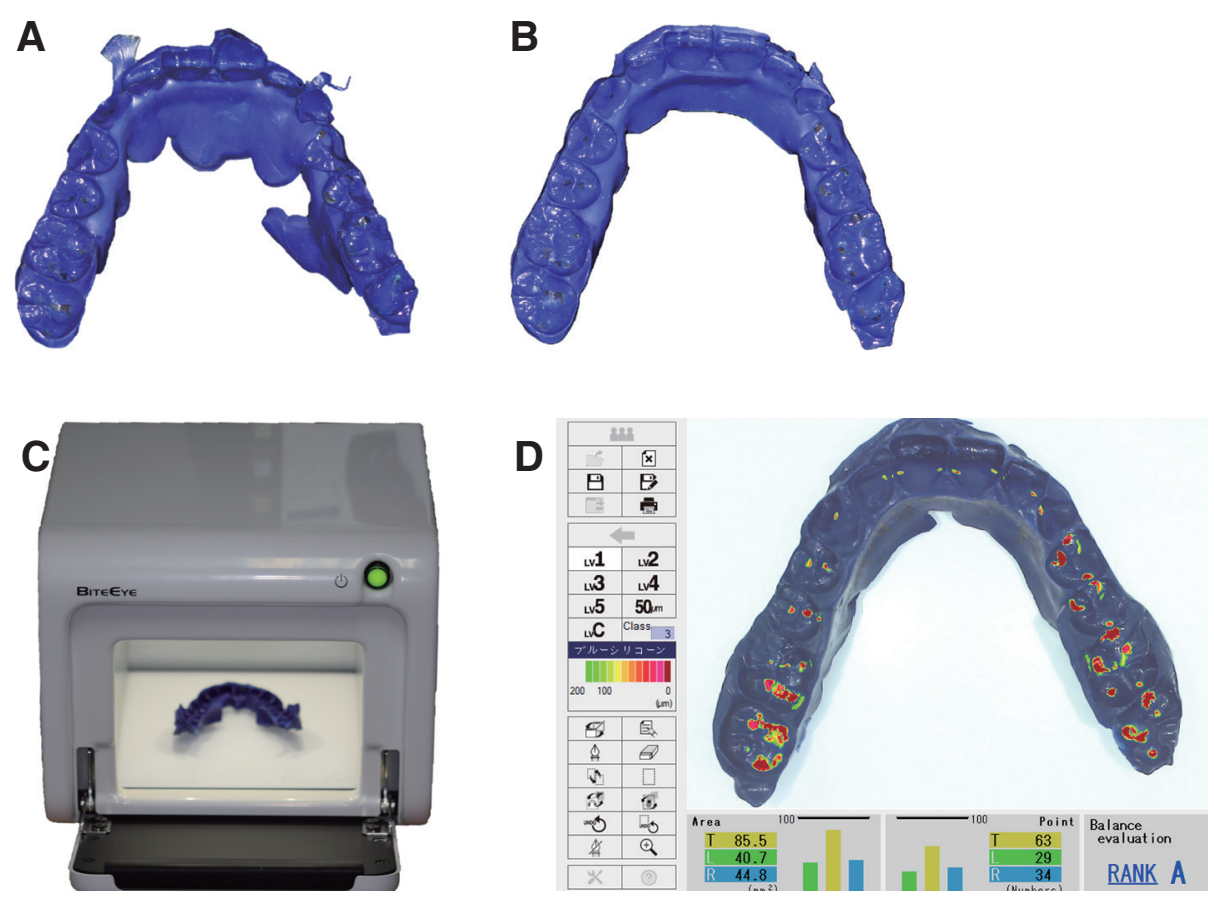

Fig. 2. Interocclusal record was modified to analyze. (A) Before modification, (B) After modification, (C) BiteEye ${ }^{\circledR}$ device, (D) Analysis of interocclusal record.

였다(Fig. 2C and 2D). 광조사교합분석기 전용 컴퓨터 소 프트웨어를 이용하여 채득한 악간관계기록을 기계 내에 위치시키고 제조사의 지시에 따라 소프트웨어 상에 나타 난 상방 제한선 위치에 악간관계기록 시편의 전치부 변연 이 넘어가지 않도록 하고 하방 제한선 위치에 시편의 후 방 변연이 넘어가지 않도록 하였으며, 중심 제한선에는 상악 좌측 중절치와 상악 우측 중절치의 치간부위가 오 도록 하여 좌우측 경계가 되도록 하였다. 프로그램 상 옵 션을 시편의 종류에 맞춰 ‘실리콘 모드’로 한 상태에서 촬 영버튼을 눌러 시편의 분석을 시행하였다. 시편 분석 시 프로그램 내 ‘영역 지정' 기능을 이용하여 각 치아마다
의 교합접촉면적을 각각 구하였다. 교합접촉면적은 치아 간 거리에 따라 0 - 4, 0 - 9, 0 - 19, 0 - 29, 0 - 39, 0 - 49, 0 - 59, 0 - 69, 0 - 89, 0 - 109, 0 - 129, 0 - 149, 0 - 179, 0 - $200 \mu \mathrm{m}$ 수준으로 분석이 가능한데 이 중 특정 치아 간 거리 수준은 임상적으로 널리 사용되는 교합점 기록재 혹은 교합접촉 확인 재료를 기준으로 shimstock 수준인 0 - $9 \mu \mathrm{m}$, 교합필름 수준인 0 - $19 \mu \mathrm{m}$, 교합지 수준인 0 $89 \mu \mathrm{m}$ 사이의 결과를 이용하였으며, 화면상에 표시되는 교합접촉면적을 기록하였다. 각각의 자세에 대해서 채득 한 시편에 대해 위의 과정을 반복하였다.

통계분석은 SPSS (SPSS Statistics 25.0, SPSS Inc., 
Chicago, USA)을 이용하여 교합접촉면적 값이 정규분 포를 보이는지 확인하기 위해 유의수준 $95 \%$ 에서 Kolmogorov-smirnov test를 시행하였고 등분산을 만족하 는지 확인하기 위해 Levene's test를 시행하였다. 그 결과 정규분포 및 등분산성을 만족하지 않아 비모수 검정을 시행하였다. 머리 위치에 따른 교합접촉면적의 변화를 알 아보기 위해 Kruskal-Wallis/one way ANOVA by ranks test를 시행하였다.

\section{결과}

치아 간 거리수준이 shimstock 수준 $(0-9 \mu \mathrm{m})$ 일 때 평균 교합접촉면적은 group S가 $20.89 \mathrm{~mm}^{2}$, group I가 $21.06 \mathrm{~mm}^{2}$, group U가 $19.73 \mathrm{~mm}^{2}$ 으로 나타났다. 교합 필름 수준 $(0-19 \mu \mathrm{m})$ 일 때 평균 교합접촉면적은 group $\mathrm{S}$ 가 $25.68 \mathrm{~mm}^{2}$, group I가 $25.69 \mathrm{~mm}^{2}$, group U가 24.37 $\mathrm{mm}^{2}$ 으로 나타났다. 교합지 수준 $(0-89 \mu \mathrm{m})$ 일 때 평균 교합접촉면적은 group S가 $55.67 \mathrm{~mm}^{2}$, group I가 56.45 $\mathrm{mm}^{2}$, group U가 $55.78 \mathrm{~mm}^{2}$ 으로 나타났다. 머리 위치에 따른 교합접촉면적의 변화는 모든 치아 간 거리 수준에 서 통계적으로 유의미한 차이가 없었다 $(P>0.05)$ (Fig. 3). 머리 위치에 따른 교합접촉면적의 유의미한 차이가 나타 나지 않았으며 이에 따라 귀무가설은 기각되지 않았다.

\section{고찰}

교합접촉면적과 머리 위치는 유의미한 관계가 없는 것 으로 나타났다. 머리 위치에 따라 교합접촉면적의 차이 를 지적하거나 하악의 위치 변화를 보고하는 문헌들이 있었다. ${ }^{9-12}$ Gupta 등 ${ }^{9}$ 은 자연치열에서 직립 자세와 고개 를 앞으로 숙인 경우에서 교합접촉면적의 변화를 보고하 였다. 하지만 해당 시험에서는 압력 감지 센서를 이용하 였다. 압력 감지 센서는 약 $100 \mu \mathrm{m}$ 정도의 두께 때문에 교합접촉면적 측정에 있어서 결과에 영향을 끼칠 가능성 이 있다. ${ }^{13,15}$ Coelho 등 ${ }^{10}$ 은 유닛 체어에서 완전히 누운 자 세를 했을 때, 앉은 자세에 비해 하악의 위치가 $1.41 \mathrm{~mm}$ 가 차이가 났다고 보고하였다. 그러나 해당 시험은 하악 의 위치변화를 본 것으로 교합접촉면적에 대한 연구는 아니었다. 본 연구에서는 자세가 유닛 체어에 앉아 뒤로 젖힌 상태였고 시험 대상은 완전한 자연치열을 가지고 있는 사람을 대상으로 하였으며 측정도 교합접촉면적에 한정하였다. 교합접촉면적은 하악의 위치 변화에도 불구 하고 최대 교두 접촉위로 폐구할 때 완전한 치열들에 의 해 보상된 것으로 추측된다.

본 시험에서 사용된 광조사교합분석기는 분석재료로 전용 악간관계기록 실리콘을 이용하였다. 이 재료는 60 초만에 굳어 빠르게 경화하고 높은 흐름성을 보이며 저

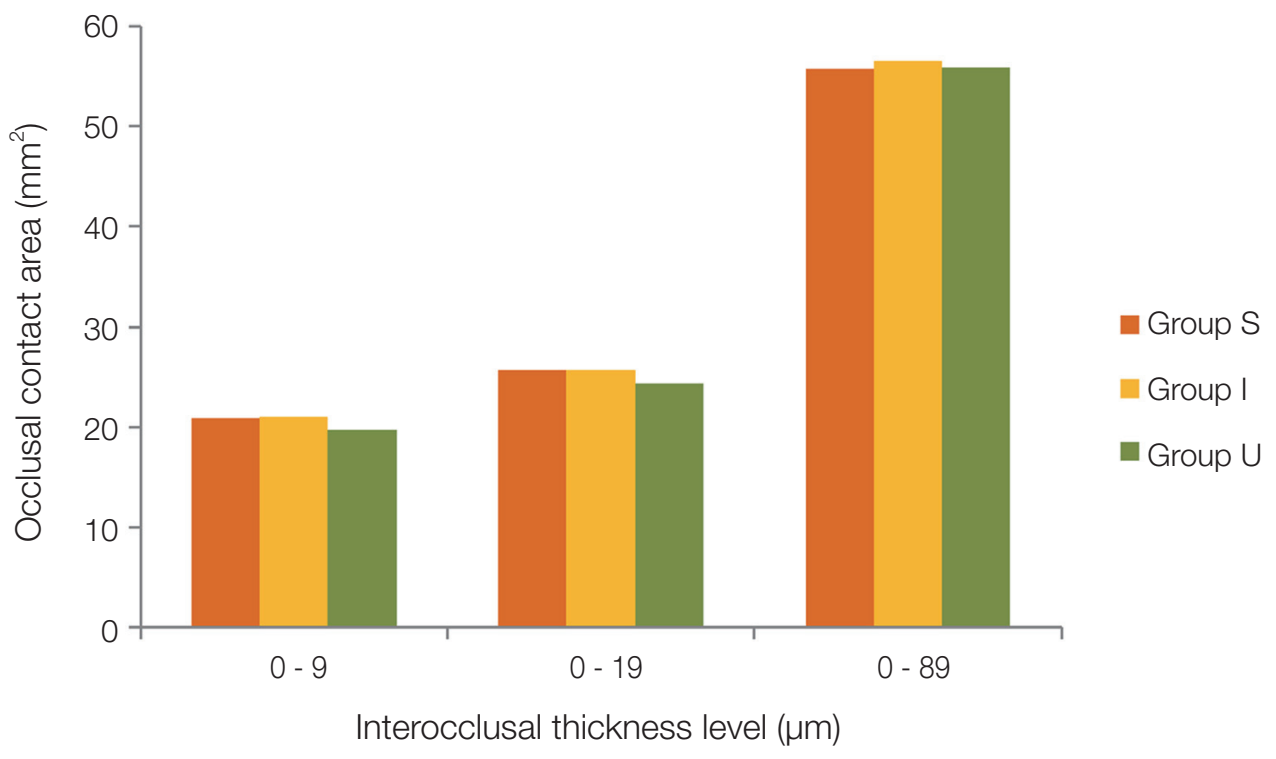

Fig. 3. Occlusal contact area according to head postures with each interocclusal thickness level. No significant differences were shown between group $\mathrm{S}$, I and $\mathrm{U}$. 
항감이 없으면서 굳은 후에는 쉽게 천공이 일어나지 않 는다. Ando 등 ${ }^{16}$ 은 악간관계기록 실리콘을 이용한 교합 접촉 분석방법은 높은 흐름성 때문에 정확하지만 빛을 투과시킨 양을 분석함에 있어 정밀한 설정이 필요하다고 하였다. $\mathrm{Bae}$ 등 $^{6}$ 은 파라핀 왁스를 이용하여 교합접촉면 적을 측정하였는데 비교적 정밀성이 떨어지는 $50 \mu \mathrm{m}$ 이 하의 교합접촉면적을 측정하기 위해 빛을 투과시켜 소프 트웨어 상 분석을 시행하였다. Lepley 등은 악간관계기 록 실리콘의 그레이 스케일(gray scale)에 대한 이차함수 를 구하여 두께를 측정하였다. 이렇듯 악간관계기록 실 리콘의 정확성에도 불구하고 측정과 분석의 어려움 때문 에 교합접촉면적 측정 시 교합지나 두께가 두꺼운 센서 와 같이 정확성에 의심이 가는 방법이 널리 사용되었다. ${ }^{20}$ 특히 두께가 두껍고 소성이 있는 재료는 교합 채득 시 교 합 인기재료나 교합 자체에 간섭을 일으켜 부정확한 결 과를 야기할 수 있다. ${ }^{13,15,20}$ 본 실험에서 사용된 전용 악간 관계기록 실리콘은 재료적인 측면에서는 흐름성이 높아 교합 인기재료나 교합 자체에 간섭을 일으키지 않으므로 정밀성과 정확성이 높다고 할 수 있고 분석적인 측면에 서는 전용 소프트웨어를 이용하므로 측정과 분석이 쉽고 정확하다는 장점이 있다.

광조사교합분석기인 BiteEye ${ }^{\circledR}$ 를 이용한 연구들을 살 펴보면 근전도(electromyography) 혹은 압력 감지 센서 와 함께 이용하여 악물기 수준에 따른 교합접촉면적의 변화 $^{21-26}$ 와 같이 교합접촉면적 자체를 분석하기 위한 문 헌들이 있었던 반면, 임플란트의 교합접촉면적이 인접 치에 미치는 영향에 대한 연구와 같이 ${ }^{27}$ 교합접촉면적을 하나의 변수로 설정하기 위해 보조적인 수단으로 이용 한 경우도 있었다. 광조사교합분석기의 신뢰도나 반복재 현성에 대한 연구도 있었다. Uchida 등 $^{28}$ 에 의하면 blue silicone과 광조사교합분석기를 이용해 교합접촉면적을 분석할 때 임상적으로 충분히 안정된 결과를 나타내어 신뢰도가 확보되어있다고 하였으며, Kubo 등 ${ }^{29}$ 에 의하면 광조사교합분석기는 상관계수 0.9 이상으로 반복재현성 이 매우 높다고 하였다.

본 연구에서는 머리 위치가 교합접촉면적과 관련되어 있는지를 살펴 보고자 하였다. 비록 머리 위치가 교합접 촉면적에 미치는 영향이 없었다는 결과이지만, 이는 임상 적으로 밨을 때 교합관계가 안정적인 환자에서 최대 교 두간 접촉위의 악간관계기록 채득 시 환자의 유닛체어의 각도나 머리 위치에 영향이 적다는 근거가 될 수 있다. 또 한 임상적으로도 광조사교합분석기를 이용해 정밀한 수
준의 교합접촉면적을 정확하고 손쉽게 측정할 수 있을 것으로 기대된다. 다만, 본 실험은 완전한 자연치열을 가 진 사람을 대상으로 최대 교두간 접촉위에서의 교합접촉 면적을 측정한 결과이므로 치열이 불안정하거나 부분적 인 치아의 상실이 있는 경우, 또는 중심위와 같이 치열에 의한 보상이 일어나지 않는 경우에는 머리 위치에 따라 다른 결과가 나타날 수 있다. 그 외에도 실리콘 악간관계 기록 채득의 신뢰성에 대한 연구가 부족하고 광조사교합 분석기 전용 분석 소프트웨어의 정확성을 고찰한 연구가 시행된 바 없으므로 이에 대한 추가적인 연구가 필요할 것이다.

\section{결론}

완전한 자연치열을 지닌 사람을 대상으로 광조사교합 분석법을 통해 교합접촉면적을 측정하여 최대 교두간 접 촉위에 대한 머리 위치가 영향을 끼치는가를 분석한 결 과, 교합접촉면적에 대해 유의미한 영향이 없는 것으로 나타났다 $(P>0.05)$. 이와 같은 결과로 교합관계가 안정 적이라면 최대 교두간 접촉위에서 악간관계기록 채득 시 머리 위치는 변수가 되지 않을 것으로 사료된다. 또한 광 조사교합분석기를 이용한 교합접촉면적의 측정은 재료 적, 측정용이성 측면으로 봤을 때 임상적으로 유용하다 고 할 수 있다.

\section{Acknowledgements}

이 논문은 2018년도 강릉원주대학교 학술연구조성비 지원에 의하여 수행되었음.

\section{ORCID}

Chang-Hwan Kim https://orcid.org/0000-0002-7416-8127 Kyung-Ho Ko https://orcid.org/0000-0002-1260-8844 Yoon-Hyuk Huh https://orcid.org/0000-0003-4072-5199 Lee-Ra Cho https://orcid.org/0000-0003-3989-2870 Chan-Jin Park https://orcid.org/0000-0003-4734-214X

\section{References}

1. Iwase Y, Saitoh I, Okamoto A, Nakakura-Ohshima K, Inada E, Yamada C, Takemoto Y, Yamasaki Y, 
Hayasaki H. Do occlusal contact areas of maximum closing position during gum chewing and intercuspal position coincide? Arch Oral Biol 2011;56:1616-23.

2. English JD, Buschang PH, Throckmorton GS. Does malocclusion affect masticatory performance? Angle Orthod 2002;72:21-7.

3. Wang YL, Cheng J, Chen YM, Yip KH, Smales RJ, Yin XM. Patterns and forces of occlusal contacts during lateral excursions recorded by the T-Scan II system in young Chinese adults with normal occlusions. J Oral Rehabil 2011;38:571-8.

4. Wilding RJ. The association between chewing efficiency and occlusal contact area in man. Arch Oral Biol 1993;38:589-96.

5. Owens S, Buschang PH, Throckmorton GS, Palmer L, English J. Masticatory performance and areas of occlusal contact and near contact in subjects with normal occlusion and malocclusion. Am J Orthod Dentofacial Orthop 2002;121:602-9.

6. Bae J, Son WS, Kim SS, Park SB, Kim YI. Comparison of masticatory efficiency according to Angle's classification of malocclusion. Korean J Orthod 2017;47:151-7.

7. Lepley CR, Throckmorton GS, Ceen RF, Buschang $\mathrm{PH}$. Relative contributions of occlusion, maximum bite force, and chewing cycle kinematics to masticatory performance. Am J Orthod Dentofacial Orthop 2011;139:606-13.

8. Bourdiol P, Mioche L. Correlations between functional and occlusal tooth-surface areas and food texture during natural chewing sequences in humans. Arch Oral Biol 2000;45:691-9.

9. Gupta S, Tarannum F, Gupta NK, Upadhyay M, Abdullah A. Effect of head posture on tooth contacts in dentate and complete denture wearers using computerized occlusal analysis system. J Indian Prosthodont Soc 2017;17:250-4.

10. Coelho MF, Cavalcanti Bd, Claro Neves AC, Jóias RP, Rode Sde M. Influence of dental chair backrest inclination on the registration of the mandibular position. J Prosthet Dent 2015;114:693-5.

11. Ohmure H, Miyawaki S, Nagata J, Ikeda K, Yamasaki K, Al-Kalaly A. Influence of forward head posture on condylar position. J Oral Rehabil
2008;35:795-800.

12. Ayub E, Glasheen-Way M, Kraus S. Head posture: a case study of the effects on the rest position of the mandible. J Orthop Sports Phys Ther 1984;5:179-83.

13. Halperin GC, Halperin AR, Norling BK. Thickness, strength, and plastic deformation of occlusal registration strips. J Prosthet Dent 1982;48:575-8.

14. Harper KA, Setchell DJ. The use of shimstock to assess occlusal contacts: a laboratory study. Int J Prosthodont 2002;15:347-52.

15. Millstein P, Maya A. An evaluation of occlusal contact marking indicators. A descriptive quantitative method. J Am Dent Assoc 2001;132:1280-6.

16. Ando K, Kurosawa M, Fuwa Y, Kondo T, Goto S. A study on measuring occlusal contact area using silicone impression materials: an application of this method to the bite force measurement system using the pressure-sensitive sheet. Dent Mater J 2007;26:898-905.

17. Millstein PL. An evaluation of occlusal indicator wax. J Prosthet Dent 1985;53:570-2.

18. Agbaje JO, Casteele EV, Salem AS, Anumendem D, Shaheen E, Sun Y, Politis C. Assessment of occlusion with the T-Scan system in patients undergoing orthognathic surgery. Sci Rep 2017;7:5356.

19. Park KW, Cho LR, Kim DG, Park CJ. Analysis of occlusal contacts using add-picture method. J Dent Rehabil Appl Sci 2013;29:45-58.

20. Kim CH, Kim DG, Ko KH, Huh YH, Cho LR, Park CJ. Considerations in the reliability of occlusal indicators and occlusal contact marks. J Dent Rehabil Appl Sci 2018;34:147-56.

21. Okada Y, Sato Y, Kitagawa N, Uchida K, Osawa T, Imamura Y, Terazawa M. Occlusal status of implant superstructures at mandibular first molar immediately after setting. Int J Implant Dent 2015;1:16.

22. Nishimori H, Iida T, Kamiyama H, Komoda Y, Obara R, Uchida T, Kawara M, Komiyama O. Comparing the occlusal contact area of individual teeth during low-level clenching. J Oral Sci 2017;59:337-42.

23. Sato Y, Kitagawa N, Terazawa M, Osawa T, Imamura Y. Time-dependent changes in occlusal status in an implant-supported prosthesis at the mandibular 
first molar from prosthesis placement to 3 months after. Int J Prosthodont Restor Dent 2018;8:44-53.

24. Imamura Y, Sato Y, Kitagawa N, Uchida K, Osawa T, Omori M, Okada Y. Influence of occlusal loading force on occlusal contacts in natural dentition. J Prosthodont Res 2015;59:113-20.

25. Komiyama O, Obara R, Iida T, Asano T, Masuda M, Uchida T, De Laat A, Kawara M. Comparison of direct and indirect occlusal contact examinations with different clenching intensities. J Oral Rehabil 2015;42:185-91.

26. Obara R, Komiyama O, Iida T, De Laat A, Kawara M. Influence of the thickness of silicone registration material as a means for occlusal contact examinationan explorative study with different tooth clenching intensities. J Oral Rehabil 2013;40:834-43.

27. Terauchi R, Arai K, Tanaka M, Kawazoe T, Baba S. Effect of difference in occlusal contact area of mandibular free-end edentulous area implants on periodontal mechanosensitive threshold of adjacent premolars. Springerplus 2015;4:703.

28. Uchida T, Komiyama O, Kubodera S, Okamoto Y, Iida T, Wakami M. The reliability of occlusal contact analysis using Blue Silicone ${ }^{\circledR}$ conformance inspection materials. J Jpn Soc TMJ 2014;26:93-9.

29. Kubo H, Sato M, Kashiwagi K, Nakagawa S, Fujii T, Tanaka J, Tanaka M. Repeatability of the occlusal contact area measurements using a BiteEye ${ }^{\circledR}$ tooth contact analyzing device. J Osaka Odontol Soc 2013;76:83-8. 


\section{광조사교합분석법을 이용한 머리 위치와 교합접촉면적의 관계}

\section{김창환, 고경호, 허윤혁, 조리라, 박찬진*}

강릉원주대학교 치과대학 치과보철학교실 및 구강과학연구소

목적: 교합접촉면적에 관련된 이전의 연구들은 교합두께 수준이나 교합측정방법 상 부정확성이 한계로 지적되어 왔다. 본 연구의 목적은 머리 위치가 교합접촉면적에 미치는 영향을 광조사교합분석법을 이용하여 조사하는 것이다.

연구 재료 및 방법: 건전한 치열을 갖는 54명(남성 44명, 여성 10명, 23 - 33세)을 대상으로 시험을 진행하였다. 머리 위치 와 교합접촉면적의 관계를 알아보기 위해 시험대상은 치과용 유닛체어에 세 가지 자세(누운 자세 $\left(0^{\circ}\right)$, 기울인 자세 $\left(45^{\circ}\right)$, 직립 자세 $\left.\left(90^{\circ}\right)\right)$ 로 하여 최대 교두간 접촉위를 이용하여 악간관계기록을 채득하였다. 광조사교합분석기 $\left(\mathrm{BiteEye}^{\circledR}\right)$ 를 이 용하여 교합접촉면적을 분석하였다. SPSS 25.0 을 이용하여 유의수준 $95 \%$ 에서 통계분석을 시행하였다.

결과:머리 위치는 교합접촉면적과 유의미한 영향이 없는 것으로 나타났다 $(P>0.05)$.

결론: 머리 위치는 교합접촉면적에 유의미한 영향이 없으므로 교합관계가 안정적이라면 최대 교두간접촉위의 악간관계 기록 채득 시 환자의 자세는 변수가 되지 않으며 광조사교합분석기를 이용한 교합접촉면적의 측정은 재료적, 용이성 측 면으로 유용하다고 할 수 있다.

(구강회복응용과학지 2019;35(2):90-7)

주요어: 교합접촉면적; 머리 위치; 광조사교합분석법; 최대 교두간 접촉위 